\title{
Application Tests of New Wetting Compositions for Wildland Firefighting
}

\author{
Joanna Rakowska* (10, The Main School of Fire Service, Stowackiego 52/54, \\ 01-629 Warsaw, Poland \\ Ryszard Szczygiet and Mirostaw Kwiatkowski, Forest Research Institute, \\ Sękocin Stary, Braci Leśnej 3, 05-090 Raszyn, Poland \\ Bozenna Porycka, Research Centre for Fire Protection - National Research \\ Institute, Nadwiślańska 213, 05-420 Józefów, Poland \\ Katarzyna Radwan, Chemika Marek Gajewski, Zebrzydowska 117c, 44-200 \\ Rybnik, Poland \\ Krystyna Prochaska, Institute of Chemical Technology and Engineering, Poznan \\ University of Technology, Berdychowo 4, 60-956 Poznan, Poland
}

Received: 10 February 2016/Accepted: 1 December 2016

\begin{abstract}
Extinguishing forest fires is a critical issue for fire brigades; fire can spread throughout vast areas in a relatively short period of time. The studies presented in this paper describe the results of laboratory and field tests of new compositions of wetting agents for extinguishing wildland fires. The studies assessed the ability to penetrate surface fuels using 0.5 and $1 \%$ solution of wetting compositions. The penetration of the liquid through the layer of the loose rotting wood with solutions of obtained wetting agents was up to 68 times faster than with water. The absorption of water droplet was even 40 times slower in comparison to wetting agent solutions. Based on laboratory research, compositions that exhibit the best wetting properties were analysed in real conditions in field tests to assess their capacity to penetrate in surface fuels, their ability to make fire barriers and their efficiency in suppressing fires of soil cover and thickets. In tests performed in $4 \mathrm{~m}^{2}$ plots, the wetting compositions hold the flames from crossing a thin firebreak for up to three times longer periods than water. The results of the studies confirmed a significant increase in efficiency when new biodegradable wetting agents are employed to extinguish forest fires.
\end{abstract}

Keywords: Wetting agents, Extinguishing fire, Fire breaks, Biodegradation, Forest fire protection

\section{Introduction}

Large-area fires comprise a major factor of long-term harmful changes to forest ecosystems and an adverse effect on the living conditions of the public. On a global scale, they cause changes in the atmosphere due to greenhouse gas emissions that are generated by fires, which contribute to the emergence of the greenhouse effect [1-4]. The sustained global tendency [5], for both the number of fires and

\footnotetext{
* Correspondence should be addressed to: Joanna Rakowska, E-mail: joanna.rakowska@wp.pl
} 
the increase in the burnt area, which is primarily caused by a warming climate [6, 7] is a cause for concern.

Each year, several hundred thousand fires burn throughout the world and destroy forest resources, shrubs and peat-bogs over a surface area of several million hectares [8-11]. Previously many countries e.g. Australia, USA and Canada, Russia, Brazil, European countries endured catastrophic fires and their rescue services encountered the difficult task of controlling a natural element that required the involvement of many rescue forces and a large amount of fire extinguishing equipment $[8,10-12]$.

These fires also pose a significant danger for urbanised areas. An effective extinguishing operation requires the use of optimum fire extinguishing technique and adequate extinguishing equipment and agents. Small fires can be suppressed using hand and ground extinguishing appliances; in the case of large fires, the application of aircraft equipment is frequently required [13].

The choice of a type of fire extinguishing agent depends on the magnitude, location and intensity of the wildfire. Water is the most common extinguishing agent; however, its efficiency is poor when it is used to extinguish the forest fires, shrubs, peat-bogs or wildland [14] due to its poor capacity to wet and penetrate the cracks of hydrophobic surface fuels. The extinguishing efficiency can be enhanced by adding extinguishing concentrates, which reduce the surface tension of water. The water based extinguishing agent are commonly used as firefighting foam for Class B fire suppression [15]. Each type of water-based firefighting medium requires the proper equipment to mix the concentrate with water in the required proportions, and the proper application equipment and techniques [16].

Wetting agents or class A foam (foaming agent) increase the effectiveness of water as an extinguishing agent by reducing the surface tension of water. The foam keeps water in contact with unburned fuel to prevent ignition of the fuel, whereas subsurface fire in forest demands adequate litter penetration by a wetting agent [17]. Some manufacturers classified wetting agents as class A synthetic agents; however, the differences among the agents pertain not only to the type of intended use but also to the type of surfactant [18]. This study presents the results of laboratory and field tests of new compositions of wetting agents. In a composition of firefighting foam, anionic surfactants or a mixture of anionic and nonionic synthetic surfactants [19] are typically applied. Aqueous film-forming foams were based on fluorosurfactants [20,21], whereas compounds that are based on protein were employed to produce protein concentrates of firefighting foam [22]. A current approach is the use of renewable compounds, readily biodegradable surfactants, e.g., polyethylene glycol fatty acid esters (POE) or alkyl polyglucosides (APG) $[23,24]$. They are found in laundry detergents and pharmaceutical and cosmetic products and have recently been employed as fire extinguishing compositions $[25,26]$. According to the patent literature, the application of APG only relates to foaming firefighting agents, such as aqueous film-forming foam [27-29].

Although no patent has been issued for the use of APG in wetting firefighting agents, these surfactants are employed in the compositions that are characterised by a superior wetting ability of the hydrophobic material, e.g., as a cleaning formulation [30] and a dust suppressing agent [31]. 
The purpose of this project is to determine a capacity of wetting agents to penetrate surface fuels in solutions with concentrations of 0.5 and $1 \%$. The compositions that demonstrated the best wetting properties in laboratory tests were examined in real conditions to assess their capacity to penetrate a surface, their capacity to make fire breaks and their efficiency in suppressing fires of soil cover and thickets.

\section{Materials}

Six wetting compositions, which contained mixtures of anionic and non-ionic surfactants, organic solvents and hydrotropic agents, were employed in the tests. The data on the components of the wetting agents and their basic physicochemical properties are listed in Table 1. The formulations of the W-50, W-52 and W-56 compositions were restricted by patents [32-37]. The formulations of the W-10, W-11 and W-32 compositions were similar to the W-50 composition but contained different proportions of compounds.

In some additional experiments, three commercial agents: Kerylo produced by WZChG "Pollena", Poland (density $1.03 \mathrm{~g} \mathrm{ml}^{-1}$, surface tension $33.8 \mathrm{mN} \mathrm{m}^{-1}$, viscosity $3.5 \mathrm{mPa} \mathrm{s}$ ), BioFor $\mathrm{C}$ produced by Bio-Ex SA, France (density $1.03 \mathrm{~g} \mathrm{ml}^{-1}$, surface tension $25 \mathrm{mN} \mathrm{m}^{-1}$, viscosity $31 \mathrm{mPa} \mathrm{s}$ ) and Prosintex A produced by Profoam, Italy (density $1.02 \mathrm{~g} \mathrm{ml}^{-1}$, surface tension $27 \mathrm{~m} \mathrm{~N} \mathrm{~m}^{-1}$, viscosity $13 \mathrm{mPa}$ s) were applied for comparison with these new proposed formulations.

\subsection{Testing Methods}

In the studies, typical laboratory tests to determine the rate of wetting and typical extinguishing fire tests were performed. The results from studies regarding the wetting and fire extinguishing of various wetting compositions in comparison to commercial agents were presented in [18].

\section{Table 1}

\section{Composition and Physicochemical Properties of Wetting Agents}

\begin{tabular}{lllllll}
\hline & \multicolumn{5}{c}{ Sample number } \\
\cline { 2 - 7 } Feature & W-10 & W-11 & W-32 & W-50 & W-52 & W-56 \\
\hline Composition & & & & & & \\
$\quad$ Anionic surfactants, \% (sodium pareth sulfate $+3 \mathrm{EO})$ & 37 & 37 & 37 & 55 & 55 & 37 \\
$\quad$ Non-ionic surfactants, \% (C13 iso,alcohol & 5 & 6 & 5 & 6 & 6 & 5 \\
$\quad+\quad$ EO and APG C8-C10) & & & & & & \\
$\quad$ Organic solvents, \% & 15 & 20 & 15 & 10 & 10 & 10 \\
Foam stabilisers, \% & 10 & 5 & 0 & 5 & 5 & 12 \\
$\quad$ Aqua, \% & 33 & 32 & 43 & 24 & 24 & 36 \\
Density, g ml & 1.03 & 1.03 & 1.00 & 1.05 & 1.03 & 1.04 \\
pH & 7.5 & 7.5 & 6.1 & 8.2 & 8.1 & 7.7 \\
Surface tension, $\mathrm{mN} \mathrm{m}^{-1}$ & 33.6 & 28.5 & 25.9 & 29.1 & 29.9 & 31.1 \\
Viscosity, mPa s & 6.9 & 7.6 & 6.1 & 10.1 & 13.8 & 6.9 \\
\hline
\end{tabular}


For each concentration of the wetting agent series, seven measurements were performed. Two extreme values of the series were rejected. The results consisted of the arithmetic mean of the measurements with a standard deviation of $2 \%$ for laboratory tests and less than $5 \%$ of the mean value for the field experiments.

2.1.1. Laboratory Tests The laboratory tests of the capacity of the elaborated compositions of a wetting agent to wet loose and pressed samples of vegetal materials were performed using a reference material in the form of powdered and screened rotting wood.

All laboratory measurements were carried out at $294 \pm 1 \mathrm{~K}$. The measurement uncertainty as the standard deviation was estimated.

2.1.2. The Determination of the Wettability of Loose Rotting Wood The study assesses the speed of penetration of a liquid through the layers of surface fuels and the amount of absorbed liquid. The test was performed for 0.5 and $1.0 \%$ solutions of six wetting compositions. The tests were performed in a column with a $12 \mathrm{~mm}$ inner diameter that was closed from below by a bottom with a thin venting tube.

The column with a known weight was filled with $1 \mathrm{~g}$ of rotting wood in an airdry state; the wood had been screened earlier with a $1 \mathrm{~mm}$ mesh screen. Subsequently, the content of the column was pressed to $3 \mathrm{~cm}^{3}$ volume and weighed with a maximum accuracy of $1 \mathrm{mg}$. The column was vertically placed in a stand and subsequently filled from above with $4 \mathrm{ml}$ of the solution. The time required for the first drop of the solution to flow out was measured. After the entire solution had penetrated, the container was re-weighed. The amount of the retained solution was determined using dependence (1)

$$
R=\frac{m_{n}-m_{0}}{m_{0}} \cdot 100 \%
$$

where $m_{n}$ represents the weight of the material after wetting $[\mathrm{g}]$ and $\mathrm{m}_{0}$ represents the weight of a sample in an air-dry state [g].

\subsubsection{The Determination of the Rate of Wetting of Pressed Rotting Wood The} tests of the capacity to wet with solutions of wetting agents were performed on the surface of $0.5 \mathrm{~g}$ pellets, which were composed of powdered forest material (rotting wood) in an air-dry state using a hand press to prepare samples for testing in a bomb calorimeter. All pellets were composed with the same number of rotations of the screw of the press.

Using a dropper, $50 \mu \mathrm{l}$ of the solution of a wetting agent with concentrations of 0.5 and $1.0 \%$ was applied on a pellet. The time of the drop penetration was measured until the pellet lost its lustre at the point at which the solution was applied.

Statistical analysis of adsorption ability was made according to the KruskalWallis test. Taking into account the lack of normal distribution application of non-parametric test was not possible. 
2.1.4. Field Application Tests In Poland, forest fire protection rules are governed by legal regulations on forests, nature conservation and fire protection. Their provisions prohibit the kindling of a fire in forests, and burning soil cover and plant residues. It is also forbidden to perform these tasks within a distance of $100 \mathrm{~m}$ from a forest. In addition, the Nature Conservation Act prohibits the burning of meadows, pastures, wastelands, roadside strips, railway routes and rushes and reed.

As a consequence of the above, the authors have not carried out studies of extinguishing forest fires at real scale or field tests using different extinguishing agents. A test for efficiency in extinguishing a forest fire using the developed wetting agent was carried out in an area of young forest dedicated to felling only.

The tests to determine the usefulness of the wetting compositions in real conditions were performed in real conditions in 120-year-old pine stands in a mixed fresh coniferous forest site. The field tests evaluated basic weather parameters, such as the air temperature, the relative air humidity, the wind speed and cloud cover, and the number of days without precipitation preceding the date of the measurement was determined.

The moisture content of forest materials was determined by the weight loss in oven-drying method using moisture analysers WPS110S produced by Radwag (Poland). The weather measurements were conducted by an automatic weather station that was located approximately $1 \mathrm{~km}$ from the experimental plots.

The moisture content of the litter in the tests was $8 \%$. The composition $\mathrm{W}-52$ was applied in an extinguishing test using an airplane, whereas the compositions $\mathrm{W}-50$ and $\mathrm{W}-52$ were applied in an extinguishing test using vehicles.

\subsubsection{The Wetting Efficiency and Extinguishing Tests Using Ground Equipment and} Aircraft The wetting efficiency and extinguishing tests were performed in areas that were deforested in connection with the expansion of the area occupied by the Bełchatów Lignite Mine (in Central Poland). Their objective was to determine the usefulness of a wetting agent for extinguishing soil cover fires using ground extinguishing equipment and aircraft. The following extinguishing equipment was employed in the tests:

- a M-18 B Dromader airplane,

- a patrol and the Mitsubishi L200 firefighting vehicle which was equipped with a mounted module with a 4001 capacity and a pump AR503SP with a $401 \mathrm{~min}^{-1}$ capacity,

- hand equipment in the form of the backpack stirrup pump-type HPE-19/H.

2.1.6. The Wetting Efficiency in the Field Conditions In the tests, the experimental plots were wetted by hand extinguishing equipment with solutions of wetting agents with selected concentrations and doses. To evaluate the agents, a reference plot, which was wetted with water that contained the same dose, and a control plot without an extinguishing agent, were employed. After the solutions of the compositions of the agents had been applied in the experimental plots, the mois- 
ture content of the upper litter and the moisture content of the rotting wood were measured. The first measurements were conducted after $10 \mathrm{~min}$, and the moisture content of the material was measured four times every hour.

2.1.7. Fire Breaks These tests assessed the usefulness of a wetting agent for making fire breaks and for direct suppression of soil cover fires. The usefulness of a wetting agent to extinguish a soil cover fire was performed using two methods: using hand extinguishing equipment and using a patrol and firefighting vehicle.

The tests of the usefulness of a preparation for making fire breaks using a backpack stirrup pump consisted of enclosing a $2 \times 2 \mathrm{~m}$ experimental plot by a fire break with a width of approximately $1 \mathrm{~m}$, which was wetted with a dose of a solution at a rate of $21 \mathrm{~m}^{-2}$. The experimental plot was oriented to ensure that one of the diagonals coincided with the prevailing wind speed.

The tests of the usefulness of an extinguishing agent for making fire breaks were conducted using a patrol and firefighting vehicle in a $5 \times 5 \mathrm{~m}$ plot enclosed by a fire break with a width that was approximately $2 \mathrm{~m}$, which was wetted with a dose of a solution at a rate of $51 \mathrm{~m}^{-2}$.

In addition to litter, both types of plots were located in places in which a layer of small felling remains, with an average thickness of $15 \mathrm{~cm}$, was located. Ten minutes after the application of an agent in the central part of the experimental plots that were enclosed by a fire break, combustion was initiated and fire spread within the plots and in the fire break. The measurements included the time at which the fire break stopped the fire, the depth of penetration by the fire into the fire break and the time of the possible crossing of the fire break by the fire.

\subsubsection{Extinguishing of Soil Cover Fires Using Ground Equipment The tests of the} usefulness of a solution of a wetting composition for extinguishing forest fires using stirrup pumps consisted of the determination of the extinguishing time and the amount of the solution applied during the suppression of a fire and the smouldering of the soil cover within a designated area of approximately $5 \mathrm{~m}^{2}$.

The tests of the usefulness of an extinguishing agent for direct firefighting using a patrol and firefighting vehicle consisted of initiating combustion in a selected part of a felling site with a layer of small felling remains with a thickness of approximately $0.5 \mathrm{~m}$ thick. After the fire had reached an area of approximately $25 \mathrm{~m}^{2}$, the extinguishing operation began at its perimeter; the entire area was subsequently damped down. In the course of the tests, the extinguishing time and the required amount of solution were measured.

2.1.9. Extinguishing Tests Using Aircraft Equipment Drops of a solution of a wetting agent - 15001 with an $0.5 \%$ concentration-were applied to a 116-year-old pine stand in a fresh coniferous forest site. Drops were applied from a height range of $10 \mathrm{~m}$ to $15 \mathrm{~m}$ above the tree crowns from an extinguishing aircraft that was flying at the speed of approximately $180 \mathrm{~km} \mathrm{~h}^{-1}$. Thirty minutes after the drop, the moisture content of the upper litter and the rotting wood were measured. 
Two types of extinguishing tests were also performed. In the first test, an extinguishing aircraft was employed to make a drop onto an area of approximately 0.1 ha in a 12-year-old pine thicket. In the second test, a patrol and firefighting vehicle and two firefighting units that were equipped with vehicles with 2500 and 50001 tanks the attempted to extinguish the burning felling remains in an area of approximately 0.1 ha.

2.1.10. Tests of Biodegradation Biodegradation tests were performed for three compositions: W-50, W-52 and W-56.

The tests for $0.5 \%$ solutions were performed according to the procedure No. 301A - Biodegradation - the decay of dissolved organic carbon (DOC) [38-40]. The prepared mixtures were aerated for 28 days at temperatures of $20^{\circ} \mathrm{C}$ to $25^{\circ} \mathrm{C}$, in diffused light. Based on the results, the DOC content in a given mixture was calculated after a specific time of biodegradation and the biodegradability of the preparation was subsequently tested in an aqueous medium. Biodegradation, which was defined as the percentage loss of DOC in the solution, in the course of the observed decay was calculated according to Equation (2)

$$
R_{t}=\left(1-\frac{C t-C B}{C A-C B A}\right) \cdot 100
$$

where $R_{t}$ denotes the percentage rate of decay in the time $t, C_{A}$ denotes the mean content of DOC in $\mathrm{mg} / \mathrm{l}$ in a container with the tested substance measured after $3 \pm 30 \mathrm{~min}, C_{t}$ represents the mean content of DOC in $\mathrm{mg} / \mathrm{l}$ after the time $t$ in a container with the tested substance, $C_{B A}$ represents the mean content of DOC in $\mathrm{mg} / \mathrm{l}$ in blind experiments after $3 \pm 30 \mathrm{~min}$ and $C_{B}$ denotes the mean content of DOC in $\mathrm{mg} / \mathrm{l}$ in blind experiments after the time $t$.

\section{Results and Discussion}

\subsection{The Determination of the Capacity to Wet Forest Material}

The laboratory tests of the capacity of the wetting agent to wet vegetal materials were performed by examinations of wetting of loose and pressed rotting wood.

\subsection{The Wetting of Loose Rotting Wood}

The tests evaluated six obtained wetting compositions: W-10, W-11, W-32, W-50, $\mathrm{W}-52$ and W-56 and three commercial agents with concentrations of 0.5 and $1 \%$ and distilled water as the reference material. The averaged results of the measurements of the particular parameters and their comparison with the results for distilled water are shown in Figures 1 and 2. The measurements were conducted in a laboratory at an air temperature that ranged from $18^{\circ} \mathrm{C}$ to $20^{\circ} \mathrm{C}$ and a relative air humidity that ranged from $70 \%$ to $80 \%$. The absorbed amount of the $0.5 \%$ solution of a new wetting composition varied between $187.7 \%$ for with the weight of dry rotting wood for W-32 and $215.4 \%$ for the $1 \%$ solution W-52. No significant 
differences were observed in the amount of the absorbed liquid between the solutions with concentrations of $0.5 \%$ and the solutions with $1 \%$ concentrations. The amount of the adsorbed solution of commercial agents was similar to that obtained with the wetting compositions (Figure 1). The time reduction of the penetration of the liquid through the layer of the loose rotting wood was distinct: $1070 \mathrm{~s}$ for water and from $15 \mathrm{~s}$ to $50 \mathrm{~s}$ for other solutions of wetting agents, with a maximum rate that is 68 times faster than water for W-52 (Figure 2). Both the developed wetting compositions and commercial agents penetrated the layer of loose rotting wood faster as $1 \%$ solutions than $0.5 \%$ solutions. Wetting agent are typically used in concentration up to $1 \%[13,18]$.

\subsection{The Wetting of Pressed Rotting Wood Pellets}

The tests were performed on six selected wetting compositions: W-10, W-11, W$32, \mathrm{~W}-50, \mathrm{~W}-52$ and $\mathrm{W}-56$ and three commercial agents with concentrations of 0.5 and $1 \%$. The averaged results of the measurements and their comparison with the results for distilled water are shown in Figure 3. For all tested solutions, a substantial increase in the rate of absorption of drops of a wetting agent into the surface fuels was observed. The dynamics of the absorption of drops of solutions with a $1 \%$ concentration was significant for the wetting compositions W-50 and $\mathrm{W}-52$. In both cases, the rate of absorption was larger by a factor of 40 compared with the rate of absorption of distilled water. For commercial agents, very good results were achieved for solutions of Kerylo and BioFor C.

Satisfactory results were also achieved for the $0.5 \%$ solutions $\mathrm{W}-50, \mathrm{~W}-52$ and $\mathrm{W}-56$, for which the rate of adsorption was reduced more than ten times in comparison to water.

Calabri [13] found that different wetting agents penetrate the wood or charcoal 6 to 8 times faster than water.

Results of Kruskal-Wallis test for the 0.5 and $1 \%$ concentration are presented in Table 2. Substantial adsorption time change is marked with bold font. Graphic

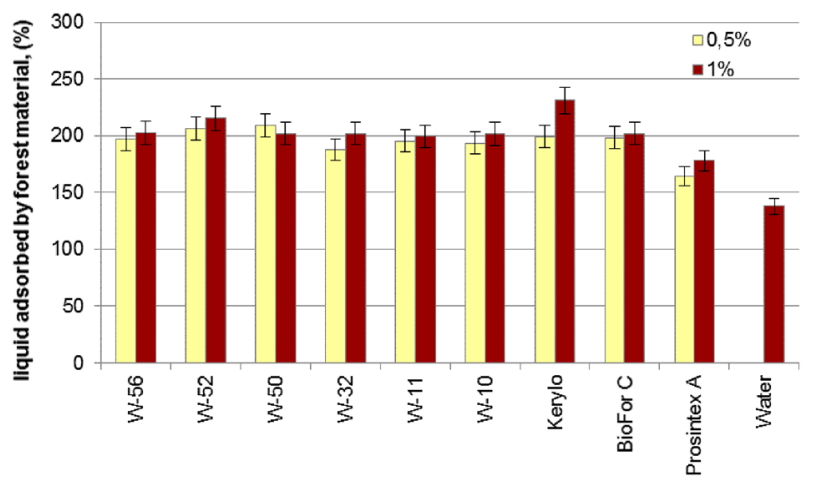

Figure 1. Amount of a liquid adsorbed by forest material in relation to the weight of rotting wood. 


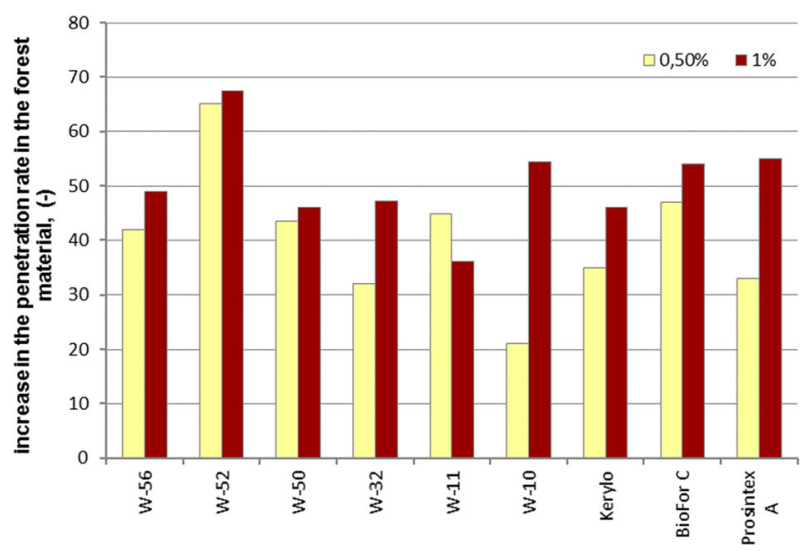

\section{Figure 2. Increase in penetration rate of wetting solutions compared with the penetration rate of water in the forest material (multiple penetration rates of water).}

diversification of adsorption time for 0.5 and $1 \%$ concentration is presented respectively on the Figure $3 \mathrm{~b}$, c.

Time of drop adsorption was substantially different for wetting composition W$50, \mathrm{~W}-52$ and W-56 comparing to water with no difference to 0.5 or $1 \%$ concentration except wetting composition $\mathrm{W}-11$ where time was substantially different only for $1 \%$ concentration. Additionally, time of adsorption for W56 is presented separately for 0.5 and $1 \%$ concentration (Figure 3d). No substantial differences were observed at this point between different concentrations. Result of KruskalWallis test was equal to 0.0736 .

\subsection{Field Tests}

In the field tests the wetting efficiency, usefulness of a wetting compositions for making fire breaks and extinguishing tests using ground and aircraft equipment were performed.

\subsection{The Wetting Efficiency in the Field Conditions}

Table 3 shows the weather conditions for the days in which the field wetting tests were performed. Due to the high costs and time-consuming field tests only one series of measurements was conducted each day.

Table 4 shows the detailed results, which were averaged from the three measurement series and relate to the capacity to wet the soil cover materials in real conditions. When analysing these materials, note that the first series was tested 3 days after rainfall, when the moisture content of litter and rotting wood exceeded $0 \%$.

For the tested compositions of wetting agents, the mean increase in the moisture content of the litter, immediately after the surface had been treated with water or a solution, was almost half the mean increase observed for water. How- 

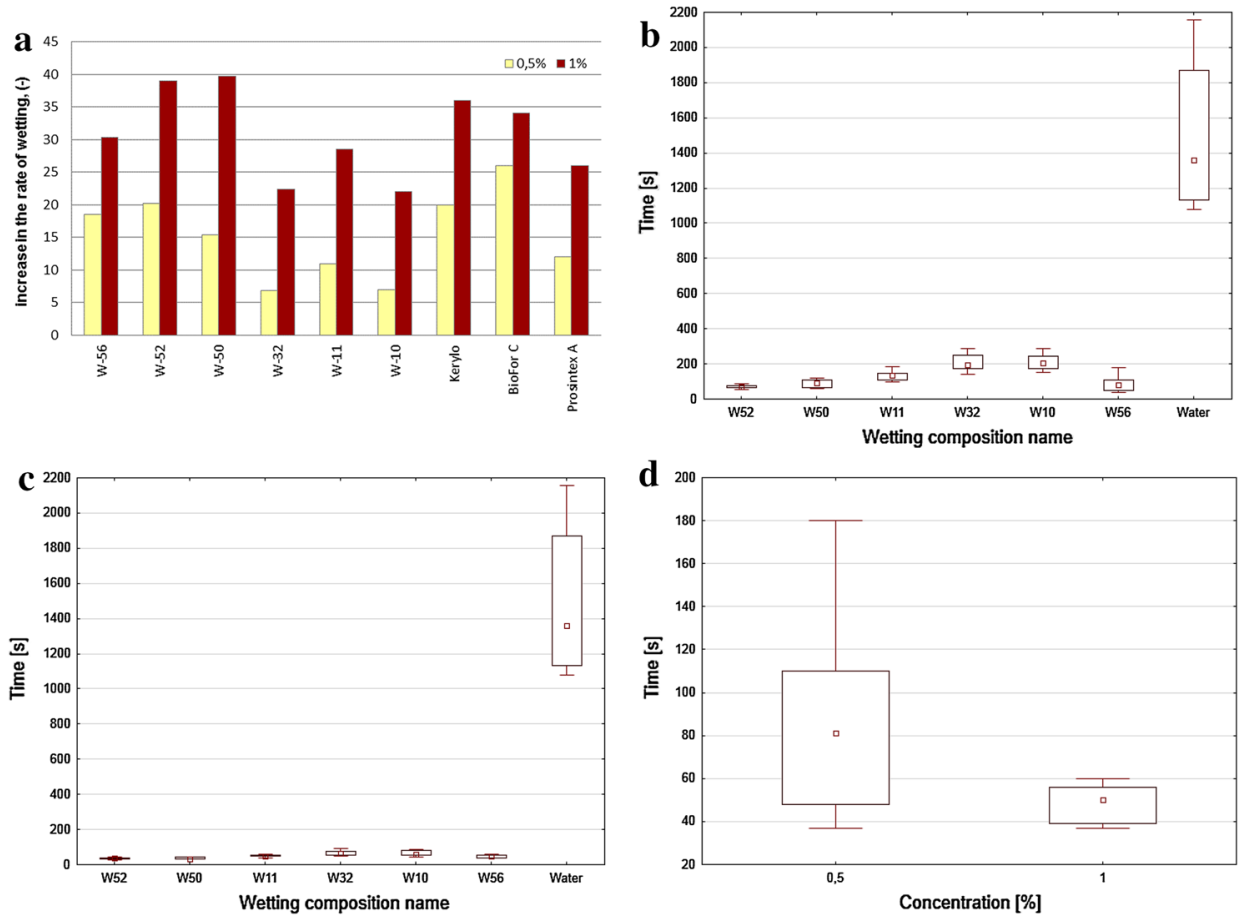

Figure 3. Time reduction of adsorption of tested solutions compared with water. (a) Increase in the rate of wetting of pressed rotting woods pellets according to the type of preparation compared with distilled water. (b) Drop adsorption time for $0.5 \%$ concentration. (c) Drop adsorption time for $1 \%$ concentration. (d) Time of adsorption for W-56.

Table 2

Results of Kruskal-Wallis Test for Each Wetting Composition

\begin{tabular}{lcccccccc}
\hline & W52 & W50 & W11 & W32 & W10 & W56 & Water & \\
\hline W52 & & 1.000000 & 0.851491 & $\mathbf{0 . 0 0 9 8 5 4}$ & $\mathbf{0 . 0 1 3 0 1 1}$ & 1.000000 & $\mathbf{0 . 0 0 0 0 1 7}$ & Concentration $0.5 \%$ \\
W50 & 1.000000 & & 1.000000 & 0.136476 & 0.170705 & 1.000000 & $\mathbf{0 . 0 0 0 6 6 3}$ & \\
W11 & 1.000000 & 1.000000 & & 1.000000 & 1.000000 & 1.000000 & 0.080945 & \\
W32 & $\mathbf{0 . 0 3 1 9 6 9}$ & $\mathbf{0 . 0 2 5 4 6 8}$ & 1.000000 & & 1.000000 & 0.088469 & 1.000000 & \\
W10 & $\mathbf{0 . 0 4 8 2 4 7}$ & $\mathbf{0 . 0 3 8 7 2 3}$ & 1.000000 & 1.000000 & & 0.111733 & 1.000000 & \\
W56 & 1.000000 & 1.000000 & 1.000000 & 1.000000 & 1.000000 & & $\mathbf{0 . 0 0 0 3 5 5}$ & \\
Water & $\mathbf{0 . 0 0 0 0 3 4}$ & $\mathbf{0 . 0 0 0 0 2 4}$ & $\mathbf{0 . 0 4 2 5 7 0}$ & 1.000000 & 1.000000 & $\mathbf{0 . 0 3 7 5 1 3}$ & & \\
& \multicolumn{1}{l}{ Concentration 1\% } & & & & & & \\
\hline
\end{tabular}

ever, the results for rotting wood differed. For solutions of wetting agents, the moisture content increased by one-fourth immediately after wetting compared in relation to water, whereas the average increase for the entire period of measure- 
Table 3

Weather Parameters and the Moisture Content of the Litter and Rotting Wood for the Measurements

\begin{tabular}{lcccccc}
\hline Day & $\begin{array}{c}\text { Air } \\
\text { temperature, } \\
{ }^{\circ} \mathrm{C}\end{array}$ & $\begin{array}{c}\text { Relative } \\
\text { air } \\
\text { humidity, \% }\end{array}$ & $\begin{array}{c}\text { Moisture } \\
\text { content of } \\
\text { litter, \% }\end{array}$ & $\begin{array}{c}\text { Moisture } \\
\text { content of } \\
\text { rooting wood, \% }\end{array}$ & $\begin{array}{c}\text { Wind } \\
\text { speed, } \\
\mathrm{m} \mathrm{s}^{-1}\end{array}$ & $\begin{array}{c}\text { Number } \\
\text { of days without } \\
\text { precipitation }\end{array}$ \\
\hline First & 23.0 & 95 & 14.0 & 57.6 & 4.2 & 3 \\
Second & 26.0 & 99 & 12.9 & 47.4 & 1.7 & 6 \\
Third & 24.5 & 88 & 13.5 & 39.5 & 3.0 & 8 \\
\hline
\end{tabular}

\section{Table 4}

Mean Increase and Standard Deviation in the Moisture Content of the
Litter and Rotting Wood During Successive Hours of Measurements,
Depending on the Type of Wetting Agent

\begin{tabular}{|c|c|c|c|c|c|}
\hline \multirow{2}{*}{$\begin{array}{l}\text { Mean increase } \\
\text { in moisture } \\
\text { content, } \%\end{array}$} & \multirow[b]{2}{*}{ Time } & \multicolumn{4}{|c|}{ Type of agent } \\
\hline & & $\mathrm{W}-50$ & $\mathrm{~W}-52$ & W-56 & Water \\
\hline \multirow[t]{6}{*}{ Litter } & $10 \mathrm{~min}$ & $10.6 \pm 1.8$ & $13.8 \pm 2.1$ & $10.8 \pm 0.9$ & $22.2 \pm 3.9$ \\
\hline & $1 \mathrm{~h}$ & $9.4 \pm 0.7$ & $9.4 \pm 0.9$ & $5.9 \pm 1.1$ & $14.5 \pm 1.8$ \\
\hline & $2 \mathrm{~h}$ & $6.1 \pm 0.8$ & $6.5 \pm 1.3$ & $4.6 \pm 0.7$ & $8.2 \pm 2.1$ \\
\hline & $3 \mathrm{~h}$ & $6.6 \pm 1.2$ & $6.0 \pm 0.6$ & $3.7 \pm 0.7$ & $7.5 \pm 1.3$ \\
\hline & $4 \mathrm{~h}$ & $5.2 \pm 0.9$ & $5.6 \pm 0.7$ & $4.0 \pm 0.6$ & $6.0 \pm 1.1$ \\
\hline & Average & $7.6 \pm 1.1$ & $8.3 \pm 1.1$ & $5.8 \pm 0.8$ & $11.7 \pm 2.0$ \\
\hline \multirow[t]{6}{*}{ Rotting wood } & $10 \mathrm{~min}$ & $11.5 \pm 2.1$ & $13.4 \pm 1.6$ & $12.3 \pm 1.0$ & $9.0 \pm 1.6$ \\
\hline & $1 \mathrm{~h}$ & $8.2 \pm 1.3$ & $14.8 \pm 4.3$ & $12.9 \pm 0.6$ & $9.3 \pm 1.8$ \\
\hline & $2 \mathrm{~h}$ & $9.8 \pm 2.3$ & $14.4 \pm 3.5$ & $13.0 \pm 1.3$ & $6.3 \pm 0.4$ \\
\hline & $3 \mathrm{~h}$ & $5.4 \pm 0.8$ & $9.7 \pm 1.2$ & $11.3 \pm 0.4$ & $7.0 \pm 0.1$ \\
\hline & $4 \mathrm{~h}$ & $8.1 \pm 1.2$ & $14.3 \pm 3.7$ & $14.6 \pm 1.7$ & $7.6 \pm 2.1$ \\
\hline & Average & $8.6 \pm 1.6$ & $13.3 \pm 2.9$ & $12.8 \pm 1.0$ & $7.8 \pm 1.2$ \\
\hline
\end{tabular}

ments was half as large compared with water. The largest difference was observed for the composition W-52. After application of wetting composition directly on the litter cover lower moisture increase was observed in the upper layer for the wetting composition than for water. Water drops were present on the upper layer of litter and did not penetrate inside. Wetting compositions, because of their lower surface tension, penetrated deeply inside the material, resulting in the higher increase of moisture comparing to water only. This particular wetting ability is crucial for temperature lowering which is decisive factor influencing tree root system and in consequence total loss in the forest stand.

\subsection{Extinguishing Tests Using Hand Equipment and Firefighting Vehicle}

The tests were performed using $0.5 \%$ solutions of three preparations with the best properties. In the tests with stirrup pumps, the wetting compositions W-50, W-52 and W-56 were employed, whereas the composition W-50 was applied in a vehicle 

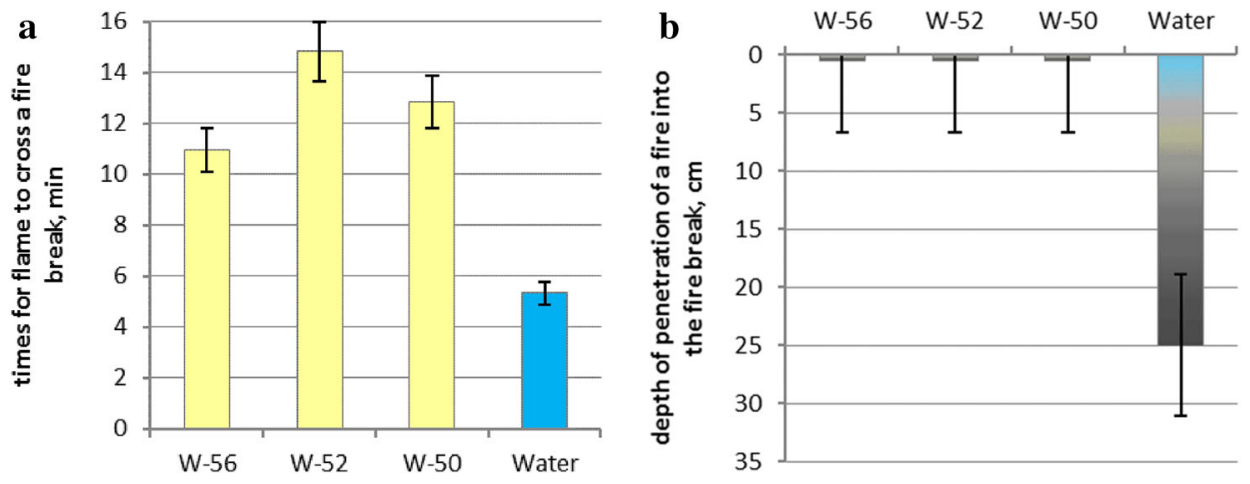

\section{Figure 4. Assessment of the usefulness of the wetting compositions for making fire breaks: (a) comparison of the time required for a flame to cross a fire break and (b) the depth of penetration of a fire below the surface of the litter into the fire break.}

with an extinguishing module. In both cases, a reference test was performed using water. The wetting composition W-56 was employed in the fire service vehicles.

\subsection{Fire Breaks}

The assessment of the usefulness of a particular wetting compositions for making fire breaks was based on the results of tests performed in $4 \mathrm{~m}^{2}$ plots, as shown in Figure $4 \mathrm{a}$. The tests were conducted using $0.5 \%$ solutions of the wetting compositions W-50, W-52 and W-56. The degree of the litter burnout, as shown in Figure $4 \mathrm{~b}$, illustrates the efficiency of the preparations in relation to pure water. The effective stopping of a fire by a fire break with a solution of the preparation W-50 is illustrated in Figure 5.

To verify the results for the preparation with the best properties, a large-scale test was performed (in a plot of $25 \mathrm{~m}^{2}$ ) using a patrol and firefighting vehicle. A fire break using the composition W-52 stopped the fire spread for 5 min and $40 \mathrm{~s}$, whereas a fire break using water held off flames for 3 min and $40 \mathrm{~s}$.

\subsection{Extinguishing Tests}

In the tests to determine the usefulness of the developed wetting compositions for extinguishing soil cover fires, three repetitions were performed for each solution. In accordance with the assumptions of the methodology, the measurements included the duration for extinguishing flaming combustion, the amount of the solution of an extinguishing agent and the time required for flaming combustion to recover. The mean results of these measurements are shown in Figures 6 and 7, and the tests are illustrated in Figures 8, 9, and 10.

The tested solutions of the wetting compositions are characterised by an extinguishing efficiency that exceeds the extinguishing efficiency of water. The use of a solution of the compositions $\mathrm{W}-50$ and $\mathrm{W}-52$ enabled the flames to be rapidly extinguished with the least amount of extinguishing agent. The time for extin- 


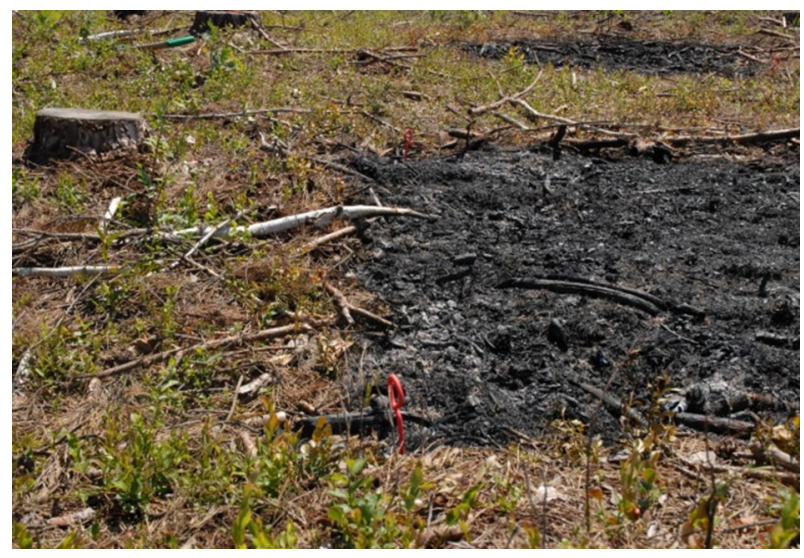

Figure 5. Effective stopping of a fire by a fire break from a solution of the preparation W-50.
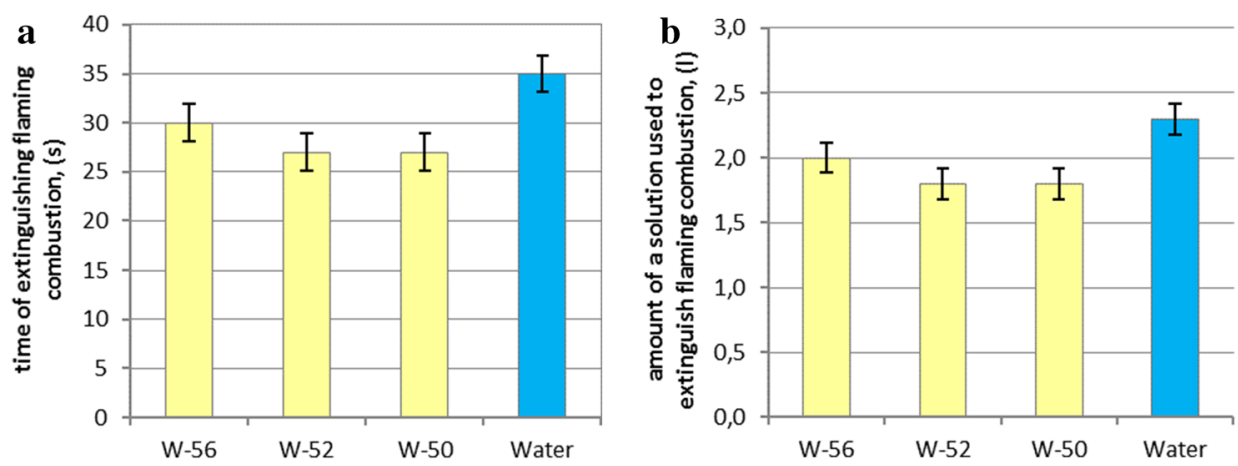

Figure 6. Effectiveness of firefighting of forest litter: (a) mean time for extinguishing flaming combustion using the developed wetting compositions and water and (b) mean amount of an extinguishing solution used to extinguish flaming combustion in wildland fire.

guishing flaming combustion on an experimental area of $2 \times 2 \mathrm{~m}$ by hand equipment with W-50 and W-52 was $27 \mathrm{~s}$, which was $8 \mathrm{~s}$ less than the time for water (more than $20 \%$ faster than extinguishing a fire on an experimental plot). The consumption of the extinguishing agent W-50 and W-52 on $4 \mathrm{~m}^{2}$ of litter was distinctly less $(\sim 20 \%)$ than the consumption for water $\left(2.31 \mathrm{on}^{2} \mathrm{~m}^{2}\right)$. The solution $\mathrm{W}-52$ with a concentration of $0.5 \%$ ensured the most sustained protection against the recovery of flaming combustion. The use of W-50, W-56 and water delayed reignition approximately $5 \mathrm{~s}$ when $\mathrm{W}-52$ protected against fire as long as observed (30 min). A delay in the re-ignition of forest material was related to the highest rate of wetting of rotting wood in the case of the solution W-52 (which was larger by a factor of approximately 1.5 compared with W-50 and W-56) and the highest 


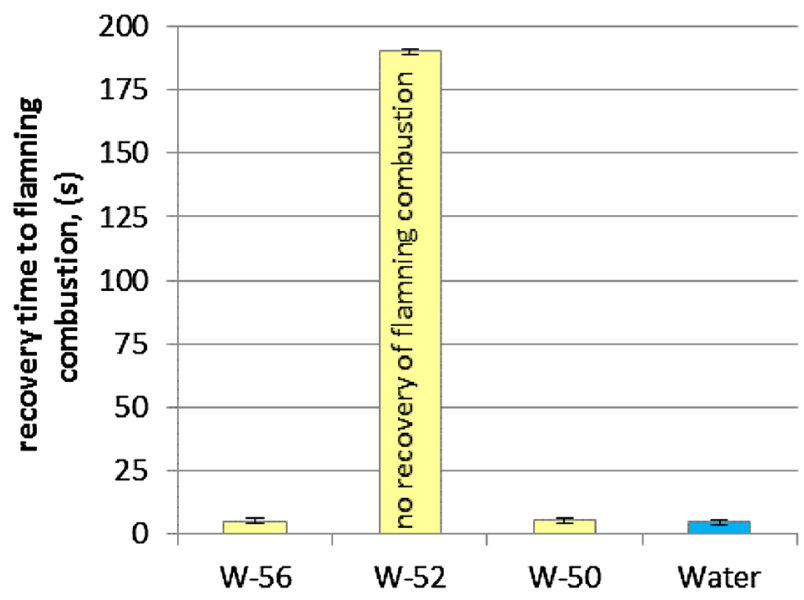

Figure 7. Recovery time to flaming combustion in wildland fire.
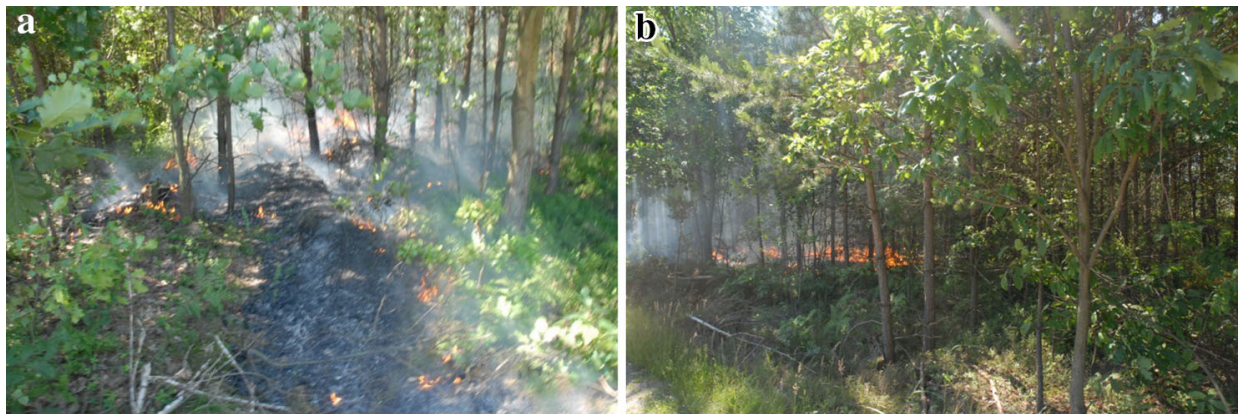

\section{Figure 8. Soil cover fire in a thicket.}

capacity of rotting wood to maintain this solution. The delay for the recovery of combustion is comparable to the delay for water (Figure 7).

Similar to fire breaks, the efficiency of extinguishing fire in a felling area was verified for a large plot; in this case, the composition W-52 was employed. Fields tests with fire were conducted for the W-52 solution, which was the most effective solution in the laboratory tests.

The time required to extinguish a fire with a surface area of approximately 0.5 ha with water supplied from firefighting vehicle was $1 \mathrm{~min}$ and $48 \mathrm{~s}$, whereas flaming combustion recovered after approximately $40 \mathrm{~s}$. When the solution W-52 was employed, the extinguishing times were $1 \mathrm{~min}$ and $30 \mathrm{~s}$ (extinguishment) and $3 \mathrm{~min}$ and $40 \mathrm{~s}$ (re-ignition), respectively.

\subsection{Extinguishing Tests Using Ground and Aircraft Equipment}

The tests were performed in stable weather conditions; the results are listed in Table 5. 


\section{Table 5}

Conditions for the Ground Extinguishing Tests

\begin{tabular}{ccccc}
\hline Hour & $\begin{array}{c}\text { Air } \\
\text { temperature, }{ }^{\circ} \mathrm{C}\end{array}$ & $\begin{array}{c}\text { Relative air } \\
\text { humidity, } \%\end{array}$ & $\begin{array}{c}\text { Wind } \\
\text { speed } \\
\text { (average), } \mathrm{m} \mathrm{s}^{-1}\end{array}$ & $\begin{array}{c}\text { Wind } \\
\text { speed } \\
\text { (maximum), } \mathrm{m} \mathrm{s}^{-1}\end{array}$ \\
\hline 10:00 & 18.8 & 49.2 & 3.4 & 7.3 \\
$11: 00$ & 19.8 & 45.9 & 3.5 & 7.5 \\
$12: 00$ & 10.5 & 42.9 & 3.7 & 7.9 \\
$13: 00$ & 21.2 & 40.2 & 3.8 & 8.7 \\
$14: 00$ & 21.7 & 42.1 & 3.8 & 8.1 \\
$15: 00$ & 21.2 & 43.0 & 3.7 & 7.7 \\
$16: 00$ & 22.1 & 41.0 & 3.7 & \\
\hline
\end{tabular}

Figures 8,9 , and 10 show the course of the two tests: with ground and with aircraft equipment. After approximately $1 \mathrm{~h}$ after the suppression of both a thicket and a felling site, the combustion process recovered in small spots in both plots, particularly in the vicinity of the stumps. To prevent the recovery of a fire and to conduct additional tests of the preparation, these small spots of recovery were damped down using the solution W-52 by a backpack stirrup pump.

Firefighting plane was involved in the thicket (young forest stand) extinguishing action where $20 \%$ of selected forest area was burnt mainly because of the high effectiveness of water bomb, covering almost whole burning area. Water bomb consisted of 15001 of water and its size on the ground was approximately an oval shape $20 \times 50 \mathrm{~m}$. In case of the clear cut area, extinguished using only ground equipment, burnt area was equal to 1.5 ha mainly because of the late begin of extinguishing process when burnt area was already around 1 ha.

\subsection{Tests of Biodegradation}

The course of the biodegradation process is shown in Figure 11. For the individual preparations, the following results were obtained after 28 days of their decay: for $\mathrm{W}-50$, the degree of biodegradation was $98.68 \%$; for $\mathrm{W}-52$, the degree of
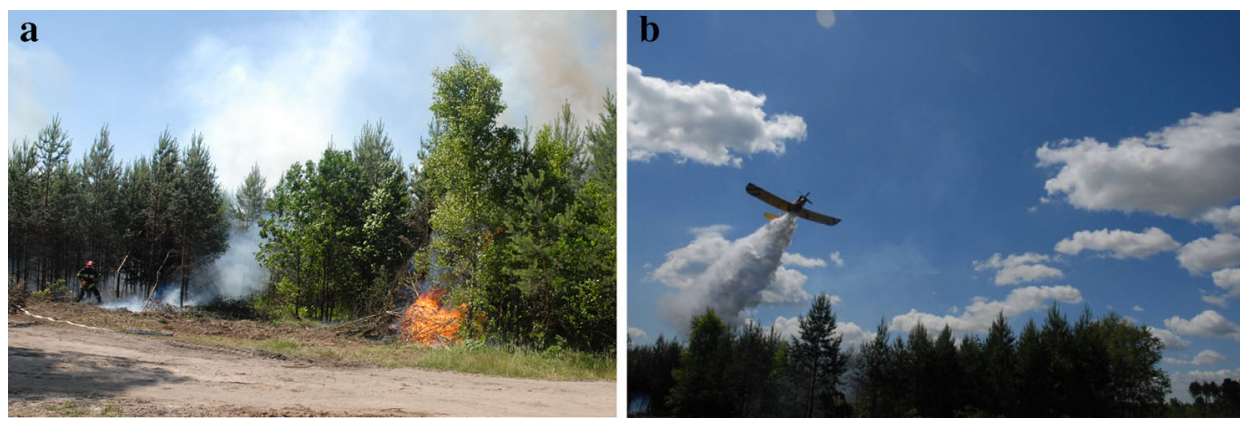

Figure 9. Burning thicket: (a) a situational view and (b) an extinguishing drop onto a burning thicket. 

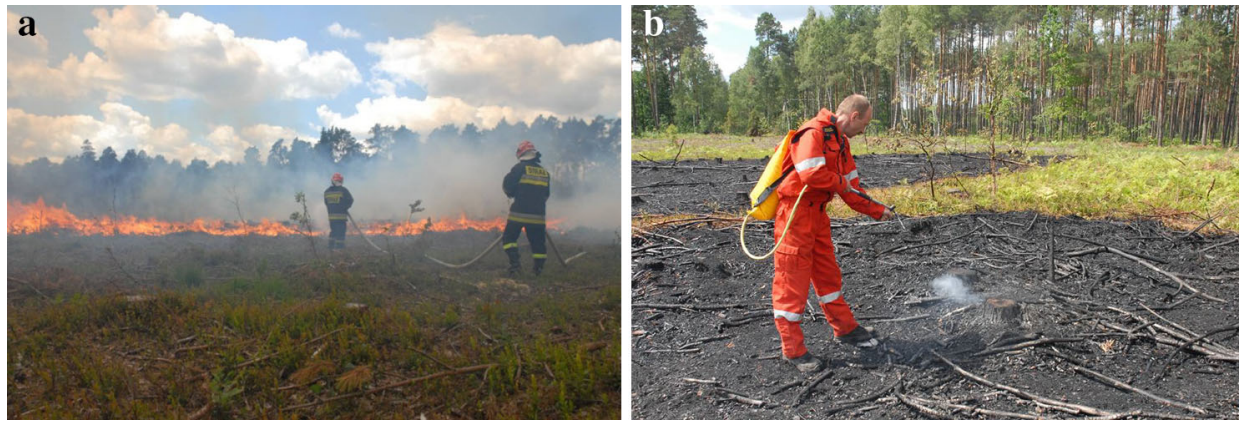

\section{Figure 10. Extinguishing of a fire: (a) on a felling site and (b) the damping down of spots where the combustion process has recovered.}

biodegradation was $98.70 \%$ and for $\mathrm{W}-56$, the degree of biodegradation was $98.73 \%$. High biodegradation of synthetic firefighting agent in studies [41] was found. According to [39], a substance is biodegradable if it loses $70 \%$ of its DOC in 28 days. The individual preparations differ in terms of the rate of biodegradation in the initial phase of the process. W-56 achieves the fastest decay rate due to the addition of a phosphate salt. The slightly lower rate for W-50 can be attributed to the use of an organic solvent with a lower rate of biodegradation. The results confirm the superior biodegradability of the tested compositions.

According to the detergent regulation [38], anaerobic biodegradability is not required for surfactants. In the obtained formulations, compounds with low biodegradability under anaerobic conditions were excluded. Surfactants hinder the

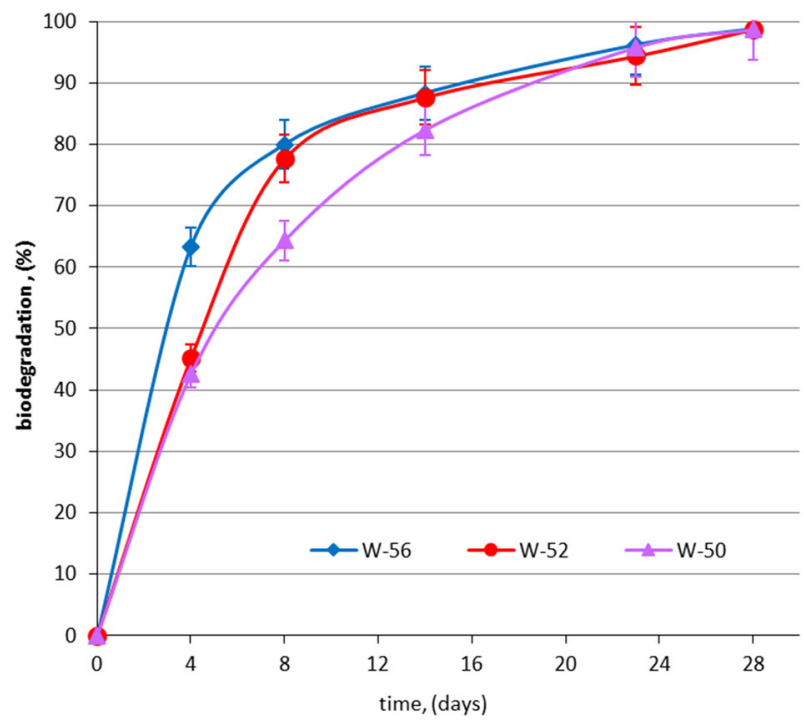

Figure 11. Biodegradation of solutions of the wetting compositions W-50, W-52 and W-56. 
penetration of oxygen into water and block the respiratory processes of aquatic organisms. Therefore, it should be prevented from input surfactants to water.

\section{Conclusions}

In the individual stages of the tests, the utility properties of the solutions of wetting agents were assessed on a current basis.

The use of wetting agents in the practice of firefighting operations in forests, peat-bogs or wildland is effective if the penetration time of a preparation is less than the penetration time for water by a factor of a dozen. With a $1 \%$ concentration, the solutions of all preparations satisfied this condition, whereas only W-50, $\mathrm{W}-52$ and W-56 satisfied this condition with a concentration of $0.5 \%$. The best results were obtained for the preparation $\mathrm{W}-50$ with a concentration of $1 \%$ and for the preparation $\mathrm{W}-52$ with a concentration of $0.5 \%$.

The penetrability was assessed using an analogous criterion, i.e., the penetration time of a solution of a wetting agent should be less than the penetration for water by a factor of 15 . In this case, all preparations satisfied the predetermined requirements for concentrations of 1 and $0.5 \%$. For both concentrations, the preparation W-52 achieved the best results. The comparison of the absorbed amount of a solution with distilled water indicates that the adsorbed amount for all the preparations and concentrations varied between 1.4 and 1.5 and was only 1.6 for the preparation W-52 with a concentration of $1 \%$.

According to the assumptions for the use of wetting agents, these preparations should be employed in small concentrations. As a result, only the preparations W$50, \mathrm{~W}-52$ and W-56 were considered for the field tests. At this stage of the tests, the preparation $\mathrm{W}-52$ demonstrated the best properties.

In the field tests of the capacity to wet the surface fuels, the largest increase in the moisture content of the upper litter was noted for water, which was followed by the preparation W-52. For rotting wood, the largest increase was achieved by the preparation W-52. However, given the small concentrations of the individual elements in the biomass of the soil cover (approximately $10 \%$ of the upper litter, approximately $70 \%$ of rotting wood and approximately $20 \%$ of lying deadwood and undergrowth), an increase in the moisture content of rotting wood is important.

The tests performed using a Dromader airplane, for which the increase in the moisture content of the litter and rotting wood was measured, also demonstrated better properties of all three preparations in relation to water, with the preparation $\mathrm{W}-52$ demonstrating the best properties.

In the extinguishing tests with hand equipment, including tests involving fire breaks and extinguishing trials, the best results were achieved by the preparation W-52.

Exceptional properties of the preparation W-52 were confirmed in the extinguishing tests performed using a patrol and firefighting vehicle and the test for extinguishing initiated fires of a thicket and a felling site. 
The results confirm the substantial increase in extinguishing efficiency for the preparation W-52 compared with water. Its extensive use can contribute to a reduction in the burnt area and the loss caused by an increase in the amount of deadwood after soil cover fires. The preparation W-52 is a suitable application in forest fire protection.

Obtained wetting agent was awarded the Gold Medal in Eureka competition at the World Exhibition on Inventions, Research and New Technologies in Brussels INNOVA 2010, Gold Medal with Mention at the International Warsaw Invention Show 2011, Madam Curie Medal for outstanding achievement in World Competition in Chemical Invention 2011 by the International Federation of Inventor's Associations and the prestige promotion emblem "Poland: Now" in 2012.

\section{Acknowledgements}

This study was supported within the statute activities No 16/BC/CNBOP-PIB/ 2011-2016 and DS-BP/32/0601/2016.

\section{Open Access}

This article is distributed under the terms of the Creative Commons Attribution 4.0 International License (http://creativecommons.org/licenses/by/4.0/), which permits unrestricted use, distribution, and reproduction in any medium, provided you give appropriate credit to the original author(s) and the source, provide a link to the Creative Commons license, and indicate if changes were made.

\section{References}

1. Cahoon DR, Stocks BJ, Levine JS, Cofer WR, Person JM (1994) Satellite analysis of severe 1987 forest fires in northern China and southeastern Sibiria. J Geophys Res 99:18627-18638. doi:10.1029/94JD01024

2. Szczygieł R, Ubysz B, Zawiła-Niedźwiecki T (2009) Spatial and temporal trends in distribution of forest fires in Central and Eastern Europe. In: Bytnerowicz A, Arbaugh M, Andersen C, Riebau A (eds) Wildland fires and air pollution. Development in environmental science, vol 8. Elsevier, Amsterdam, pp 233-246

3. Narayan C, Fernandes PM, van Brusselen J, Schuck A (2007) Potential for $\mathrm{CO}_{2}$ emissions mitigation in Europe through prescribed burning in the context of the Kyoto Protocol. For Ecol Manag 251:164-173. doi:10.1016/j.foreco.2007.06.042

4. Chiriacò MV, Perugini L, Cimini D, D’Amato E, Valentini R, Bovio G, Corona P, Barbati A (2011) Comparison of approaches for reporting forest fire-related biomass loss and greenhouse gas emissions in southern Europe. Int J Wildl Fire 22:730-738. doi:10.1071/WF12011

5. Hanson DA, Britney EM, Earle CJ, Stewart TG (2013) Adapting Habitat Equivalency Analysis (HEA) to assess environmental loss and compensatory restoration following severe forest fires. For Ecol Manag 29:166-177. doi:10.1016/j.foreco.2012.12.032 
6. Szczygieł R, Ubysz B, Piwnicki J (2007) Impact of global warming on the occurrence of forest fire in Poland. In: Proceedings of the 4th international wildland fire conference, Seville, 13-17 May 2007

7. Fernández-Fernández M, Gómez-Rey MX, González-Prieto SJ (2015) Effects of fire and three fire-fighting chemicals on main soil properties, plant nutrient content and vegetation growth and cover after 10 years. Sci Total Environ 515-516:92-100. doi:10.1016/j.scitotenv.2015.02.048

8. Szczygieł R (2012) Wielkoobszarowe pożary lasów w Polsce (Large-area forest fires in Poland). Fire Saf Tech 26(1):67-78(in Polish)

9. Liodakis S, Antonopoulos I, Kakardakis T (2010) Evaluating the use of minerals as forest fire retardants. Fire Saf J 45:98-105. doi:10.1016/j.firesaf.2009.11.002

10. Gill AM, Stephens SL, Cary GJ (2013) The worldwide "wildfire" problem. Ecol Appl 23(2):438-454. doi:10.1890/10-2213.1

11. Penman TD, Nicholson AE, Bradstock RA, Collins L, Penman SH, Price OF (2015) Reducing the risk of house loss due to wildfires. Environ Model Softw 67:12-25. doi:10.1016/j.envsoft.2014.12.020

12. Salis M, Laconi M, Ager AA, Alcasena FJ, Arca B, Lozano O, Fernandes de Oliveira A, Spano D (2016) Evaluating alternative fuel treatment strategies to reduce wildfire losses in a Mediterranean area. For Ecol Manag 368:207-221. doi:10.1016/j.foreco. 2016.03.009

13. Calabri G (1980) The use of aircraft for forest protection against fire in Italy, trends in airborne equipment for agriculture and other areas. In: Proceedings of a seminar organized by the United Nations Economic Commission for Europe, Warsaw, 18-22 September 1978, pp 345-348. doi: 10.1016/B978-0-08-022425-1.50049-8

14. Hansen R (2012) Estimating the amount of water required to extinguish wildfires under different conditions and in various fuel types. Int J Wildl Fire 21:525-536. doi:10.1071/ WF11022

15. Magrabi SA, Dlugogorski BZ, Jameson GJ (2002) A comparative study of drainage characteristics in AFFF and FFFP compressed-air fire-fighting foams. Fire Saf $\mathbf{J}$ 37(1):21-52. doi:10.1016/S0379-7112(01)00024-8

16. Laundess AJ, Rayson MS, Dlugogorski BZ, Kennedy EM (2012) Suppression performance comparison for aspirated, compressed-air and in situ chemically generated class B foams. Fire Technol 48:625-640. doi:10.1007/s10694-010-0155-z

17. International Association of Fire ChiefsNational Fire Protection Association (2012) Fundamentals of fire fighter skills. Jones \& Bartlett Publishers, Burlington, p. 573

18. Rakowska J, Prochaska K, Twardochleb B, Rojewska M, Porycka B, Jaszkiewicz A (2014) Selection of surfactants as main components of ecological wetting agent for effective extinguishing of forest and peat-bog fires. Chem Papers 68(6):823-833. doi:10.2478/s11696-013-0511-9

19. Sakamoto N, Akiyama M, Mizota C, Kawahara T, Hatae S, Uezu K, Kawano T, Akiba I (2012) Water-blown fire extinguishing agent composition and aqueous foam fire extinguishing agent. Patent WO 2011/046188, Japan

20. Quinete N, Orata F, Maes A, Gehron M, Bauer KH, Moreira I, Wilken RD (2010) Degradation studies of new substitutes for perfluorinated surfactants. Arch Environ Contam Toxicol 59:20-30

21. Bowen M, Xie Y, Havelka-Riv P (2013) Aqueous fire-fighting foams with reduced fluorine content. WO Patent 2012045080 A1, US

22. Thomphson G (1989) Film forming fluoroprotein foam concentrate WO1988003425A1, UK

23. Kjellin M( (2010) Surfactants from renewable resources. Wiley, Chichester 
24. Wang P (2014) Application of green surfactants developing environment friendly foam extinguishing agent. Fire Technol 51:503-511. doi:10.1007/s10694-014-0422-5

25. O’Lenick AJ Jr, Smith DA, Anderson D (2005) Personal care products based upon surfactants based upon alkyl polyglucoside quaternary compounds. Patent US 6881710B1,

26. Brix P, Kersting H-J (2009) Foam fire-extinguishing agents. EP Patent 0300070, DE

27. Norman E, Regina A (1993) Alcohol resistant aqueous film forming firefighting foam. WO Patent 1991001160A1, US

28. Achtmann H (1999) Biodegradable foam compositions for extinguishing fires. US Patent 5882541 A1, US

29. Robinet N, Smett C, (2014) Fire fighting foam composition. Patent US 20140138104 A1, US

30. Szewczyk G, Gambogi J, (2004) Liquid cleaning composition having improved grease removal. Patent WO 2004090086, USA

31. Winstanley R, Swartzlander M, Cook T (1993) Use of alkyl glycosides for dust suppression. Patent WO 1991000866 A1, USA

32. Twardochleb B et al (2012) Sposób otrzymywania środka zwilzającego. Patent PL 213275, PL

33. Twardochleb B et al (2012) Sposób otrzymywania środka zwilzającego. Patent PL 213276, PL

34. Twardochleb B et al (2012) Sposób otrzymywania środka zwilzającego. Patent PL 213277, PL

35. Twardochleb B et al (2012) Środek zwilzający. Patent PL 213280, PL

36. Twardochleb B et al (2012) Srodek zwilzający. Patent PL 213279, PL

37. Twardochleb B et al (2012) Środek zwilzający. Patent PL 213278, PL

38. Regulation (EC) No 648/2004 of the European Parliament and of the Council on detergents

39. OECD Test Procedure No. 301A-OECD Guidelines for the Testing of Chemicals (301), Ready Biodegradability, adopted on 17.07.1992

40. PN-EN ISO 7827:2001 Water quality. Evaluation of the "ultimate" aerobic WPbiodegrad ability of organic compounds in an aqueous medium. A method by analysis of dissolved organic carbon (DOC)

41. Król B, Prochaska K, Chrzanowski $Ł$ (2012) Biodegradability of firefighting foams. Fire Technol 48(2):173-181 